\title{
Factors enhancing the performance of SMEs' services sectors: A conceptual framework
}

\author{
Norazlina Mohd Darus ${ }^{1, *}$, Ahmad Rozelan Yunus ${ }^{2}$, Noor Watee Rahman ${ }^{3}$ \\ ${ }^{1}$ Faculty of Technology Management and Technopreneur, Universiti Teknikal Malaysia Melaka (UTeM), Melaka, Malaysia \\ ${ }^{2}$ Center of Technopreneurship \& Development (C-TED), Universiti Teknikal Malaysia Melaka (UTeM), Melaka, Malaysia \\ ${ }^{3}$ Department of Social Sciences Development, Faculty of Human Ecology, Universiti Putra Malaysia (UPM), Serdang, Selangor, \\ Malaysia
}

\section{A RTICLE INFO}

\section{Article history:}

Received 6 November 2016

Received in revised form

7 January 2017

Accepted 22 January 2017

\section{Keywords:}

Innovation

Intellectual

Capital

Quality

\begin{abstract}
A B S T R A C T
Small and Medium Enterprises (SMEs) services sector should be competent and capable enough to compete in the international arena. Hence, this conceptual paper is identifying challenges factors that could examine the enhancement of business performance, survival and success. Consequently, SMEs of services sectors' performance must also shift into the global knowledge-based economy. Therefore, the SMEs' business success sustainability highly depends on factors such as innovation, quality and intellectual capital. Furthermore, the strong knowledge of new challenges enables them to access the information of recent customer preferences, added values with current technologies. As a result, this study strives to investigate the factors that enhance the performance of SMEs services sector. In the end, this study, it is expected to contribute to new information and data support to the SMEs' in enhancing their performance in the services sector in central part of Malaysia as well employees, students and researchers. This would be the enabler solution for future challenges.
\end{abstract}

(C) 2017 The Authors. Published by IASE. This is an open access article under the CC BY-NC-ND license (http://creativecommons.org/licenses/by-nc-nd/4.0/).

\section{Introduction}

The Small and Medium Enterprises (SMEs) remains the vital focus for the economic development that providing imperative functions to the country. Even their performance look very promising, but something to ponder is whether Malaysia could reach to high income nation as planned. Meanwhile, entering the international businesses is decorously necessary especially in the liberalisation arena which Malaysia has introduced the open door concept in business where the internal market share expected to shrink tremendously. On the other hand, at present Malaysia is positioned at the ranking of 24th on the global competitiveness index 2014 (Schwab, 2014). Henceforward, it is necessary for SMEs services sector to benchmark their businesses with the international standard. Measurement of SMEs performance enhancement factors as well as competencies and capabilities globally should be

\footnotetext{
* Corresponding Author.

Email Address: norazlina3@gmail.com.my (N. M. Darus) https://doi.org/10.21833/ijaas.2017.03.025

2313-626X/C 2017 The Authors. Published by IASE.

This is an open access article under the CC BY-NC-ND license

(http://creativecommons.org/licenses/by-nc-nd/4.0/)
}

accessible within the rapid and aggressive business atmosphere. However, in benchmarking process, the most important factor for product and services is the enabling factor of innovation, improving efficiency and competitiveness of high quality, as well as having the intellectual capital for the business to be competitive. Intellectual capital considered as the most important resources for competitive organizations in the Knowledge-based economy (Khalique et al., 2011a).

\subsection{Importance of SMEs services sector}

Literature on service sector has increased substantially along the last two decades particularly on some specific activities. Despite, recent and important advances, services are still lacking of considerable attention by researchers and frequently underestimated by politicians (Cuadrado, 2013). However, Malaysia is very positive in enhancing the services sectors through its global knowledge-based economy strategy, Malaysian Institute of Economic Research (MIER, 2011). In accordance to this perhaps benchmarking towards developed countries like United Kingdom (UK) and gaining intensive knowledge of services sector perhaps the best solution (June and Khar, 2014). Services represent 
the fastest growing sector of the global economy and account for two thirds of global output, one third of global employment and nearly $20 \%$ of global trade (WTO, 2016). However, numerous SMEs of services sectors are lack of capacity to compete in a large market share. The economic development of Malaysia merely depending on SMEs which possesses very limited means. SMEs forced their activities and struggling against the uncertainty challenges when the international trade has become a critical component of Malaysia's economic engine. In the current competitive and challenging economic scenario, services sector is important to remain strong and resilient in order to drive overall economic expansion.

Additionally, the Third Industrial Master Plan anticipates that services will represent over $65 \%$ by 2020 and the sector has been receiving increasing interest from investors. During 2011 the services sector captured RM64.4 billion or $43.3 \%$ of total approved investments, followed by manufacturing (37.8\%). In contrast with the latter, investment in services originated mostly from domestic sources (74.8\%) (MITI, 2011). SMEs services sector improvement and efficiency would enhance the internal delivery system of the country that benefits to the citizen, so that it will be recognized by other countries. This recognition drive to inculcating thrust of service quality and therefore the valueadded offerings via ideas of good intellectual capital that will expand the share market (Fig. 1).

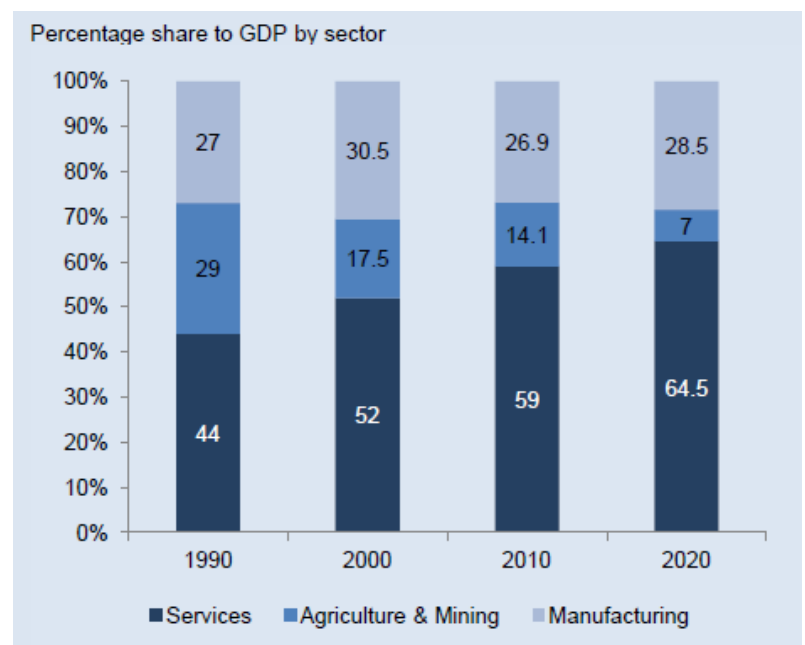

Fig. 2: Services increasingly constitute the backbone of the Malaysian Economy (MITI, 2011; 2012)

\subsection{Concept of SMEs}

Most of SMEs play significant role in stability, job creation and economic development of a nation (Fritsch and Storey, 2014; Mazzarol et al., 1999). In this research, Small and Medium Enterprises defined as companies with annual sales turnover and number of full time employees as per the new revision of 2013. Beforehand, the SME definition reviewed from year 2005, considering price inflation, structural changes and change in business trends. The new SME definition endorsed at the 14th
National SME Development Council (NSDC) Meeting in July 2013 and simplified as:

- Manufacturing: Sales turnover not exceeding RM50 million OR full-time employees not exceeding 200 workers.

- Services and other Sectors: Sales turnover not exceeding RM20 million OR full-time employees not exceeding 75 workers.

In this study, SMEs covers businesses in services sectors. Services refer to all services including distributive trade, hotels and restaurants, business, professional and ICT services, private education and health, entertainment, financial intermediation and manufacturing related services such as research and development (R\&D), logistics, warehouse, engineering, etc. In this category, the SMEs companies are mostly sole proprietorships, partnerships or private limited company entity. A business will be deemed as an SME if it meets either one of the two specified qualifying criteria, namely sales turnover or full-time employees, whichever is lower. If a business fulfills either one criterion across the different sizes of operation, then the smaller size will be applicable. For example, if a firm's sales turnover falls under microenterprise but employment falls under small, the business will be deemed as a microenterprise.

\subsection{Problems faced by SMEs of service sectors}

The historical background considering services as unproductive activities still persist. Many policy makers continue considering service as second order activities for economic growth. Nevertheless, these attitudes are changing rather quickly, particularly in the most developed countries. They are many reasons supporting the need of paying more attention to the role of services activities in our societies (Cuadrado, 2013). The services sector is predicted to accept greater role in generating growth, broadening the economic base and increasing exports in the progressive liberalisation process. Moreover, SMEs play an important role in building the economies after the recession (Soininen et al., 2012). Further, Malaysia needs to increase its diversification of services sectors export arrangement into more promising offerings in order to shift its competition with the emergence of new manufacturing hubs such as Vietnam and Indonesia, which expected to offer lesser operating costs and prices with similar standard of quality.

Besides, SMEs services sectors required to shift business to knowledge-based economy to better improvement of economy comparable with developed nations. SMEs services sectors would lead to the economic growth on their own and essential for the transformation of manufacturing and primary sectors. In going forward, actions required to facilitate the growth of services sector by creating more competitive and vibrant market conditions. 
These measures expected to enhance foreign direct investment, while promoting a more conducive and competitive environment for the domestic industry that will end contribute further to Malaysia's economic growth (MITI, 2012). Moreover, SMEs domestically are deficient in knowledge of product and services, financial of $R \& D$ and innovative. Externally, SMEs lack of skilled workers and competition in the regional economic agreement, unreasonable operational cost and raw material, incapable of managing quality products and services. Therefore, the capability evaluations for Malaysian SMEs are necessary before engaging international business (Fariza, 2015).

In addition, the contribution of SMEs services sectors to real GDP considered a bit too low in comparison to the developed nations. Malaysia has to move forward to be side by side with the developed countries, even though, its contribution at present higher than Thailand and Indonesia. In most countries, SMEs has played important role in the economy because they provide opportunity for job creation and improvement, exports, as well as suppliers in other industries. Small and medium enterprises (SMEs) have been the backbone of economic growth of an economy in driving industrial development. SMEs play a big role in national economies by providing job opportunities and supporting the big industries.

\section{Factors that challenges performance}

There are no successes guaranteed for SMEs competing in international activities and even internally. Further, indirectly SMEs involved in international business activities even though they are not running business overseas. Whether or not SMEs have to accept the liberalisation existence once government announce that Malaysia is adopting the open door concept for businesses. The government's enforcement of liberalisation into the services sector because it is expected to benefit the country in increasing growth and enhanced economic performance encourages higher levels of private investment and job creation. Liberalisation issue is still new, it is doubt that SMEs do understand that the real objective of the government which to achieve high-income nation status by 2020 . The challenge is that liberalisation activities are affecting the SMEs daily businesses and something must be done and get ready in order for them to stay competitive.

Experiences from other countries have to be adopted as the model for SMEs to face the challenges as the success rates are varies between countries to another. For instance, Das (2010) observed that country groups like East Asia in the past, China and India in the present have benefited immensely from economic and financial liberalisation drive to inequality and poverty among the self-employed increased in Mexico; as the economy stabilised inequality started to go down, but poverty kept increasing (Popli, 2010). Similarly, Obokoh (2008) showed that most Nigerian SMEs still find it difficult to compete and merely struggle to survive the liberalised economic environment in Nigeria in spite of the policies to assist the development of small and medium sized enterprises (SMEs). Political and economic liberalisation and stability of political system have a significant effect on the financial development of the African continents (Michael and Milambo, 2010). Even there are successes and fail facts, choices are SMEs themselves.

SMEs in the services sectors challenges rarely discussed in previous literatures, but they have to observe challenges directions both domestic and external environment. This is because of the contribution of services to real GDP in Malaysia is low in comparison to the developed nations. The lowest service contribution of Developed Nations was at $68 \%$ as illustrated in Fig. 2. Malaysia has to move forward to be at par with the developed countries, even though, its contribution higher than Thailand and Indonesia.

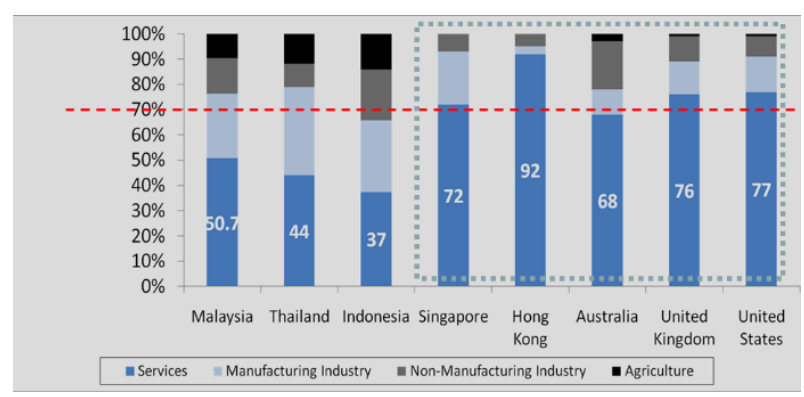

Fig. 2: Services sector benchmarking-sectoral share (\%) of GDP (Schwab, 2014)

\subsection{Innovation challenges}

Innovation becoming rampant due to the knowledgeable customer demand. In comparison in the old days, the innovation of communication application on the mobile phone for instance becoming more efficient. Instead of talking through it, now plenty of communication ways such as real time messaging are available which in reasonable or reduces charges. However, in the entrepreneurial aspects such as innovativeness, pro-activeness and risk taking carry valuable rewards in terms of organizational performance, since they represent the firm's philosophy of how to conduct a business especially in hostile or technologically sophisticated environments (Lisboa et al., 2011).

Similarly, it is necessary for SMEs services sectors to face the innovation challenges in every part of their offerings especially in rapid changing of technology. Thus, innovation challenges are necessary for efficiency of services performance. Moreover, in the competing environment, rapid changes of technology, SMEs are focusing on making innovation as the main driver for sustainable competitive advantage (Dadfar et al., 2013). Services product with excellent innovated attributes has no doubt be attracted locally and internationally. Thus, SMEs with innovation more likely to export 
successfully and generate growth compared to noninnovating firms (Love and Roper, 2015).

In this study, the most important innovation factors model developed by Beyza et al. (2014), Research on Determining Innovation Factors for SMEs was adopted. All the innovation factors are financial, firm's size, institutional, technological, consumer preferences, economic, culture, management skills, market orientation, competitive advantage learning and capability. These elements are expected covering the whole aspect of innovation factors.

\subsection{Quality challenges}

Quality credibility of offerings in services industry appears to be potential and important issues for SMEs Malaysia. Services offerings must embedded with a kind of quality assurance or come in the form of recognition and reputation. At present, liberalisation has resulted high competition in quality, marketing, profit margin and customer satisfaction (Kumar and Singh, 2012). Therefore, in compliance with quality management it is necessary for companies to be bestowed with national and international awards (Talib et al., 2013).

In reaching new customer in the liberalisation era, SMEs has to address the changes in trade demand has driven the trend for global trade liberalisation via multilateral and regional trade agreements which would enlarge the market accessibility for services sectors. Quality factors demanded by each customer may vary. However, drawing a quality standard would be the best practice for SMEs and the basic quality of offerings must be made available. For instance, SMEs services do not offer tangible product, but their offerings with high professionalism, reliability and responsiveness attracting the customer more. No doubt that liberalisation needs SMEs to introduce comprehensive quality assurance.

This study is adopting the 10 dimensions as these are the most suitable factors for this study. The factors or dimensions are tangible, reliability, responsiveness, communication, credibility, security, competence, courtesy, understanding the customer and access (Parasuraman et al., 1988). This model has also been investigated in four service firms such as a bank, a credit-card company, an appliance repair and maintenance services, and a long-distance telephone company. There would be another contribution when this studies involving the surveying professionals in Malaysia.

\subsection{Intellectual capital challenges}

Intellectual capital is very important intangible resource in crewing SMEs in the liberalisation arena. Intellectual capital does not belong to how many certificates a person has, nor the highest education attainment but from a positive and effective experienced person. This kind of person may boom SMEs with the attitude possessed which will thrive for the best of the business performance, stay focus and always positive. Intellectual capital is not just know-how, but having positive attitude, agility, networking, adapting to changes and loyal.

The challenges part for SMEs to capture is the satisfaction from excellent human capital, having to train and develop them. Additionally, retaining them is another question, as well as securing the secret of good business process and practice to the competitors through a very limited financial source. Besides, challenges in maintaining good relationship with stakeholders is imperative to gain trust. An organization will find difficult to achieve its performance goals if still surrounding with poor procedures and systems to deploy necessary resources and track its actions. In a knowledgebased economy, organizations are managed based on intellectual capital, and they are completely depends upon the intellectual capital. Intellectual capital is a critical source for organizations to take competitive advantages (Khalique et al., 2011b).

The author agreed to adopt the most widely accepted framework of intellectual capital that consists of human capital, structural capital and relational capital (Chen, 2008; Chu et al., 2006; Herremans et al., 2011; Hsu and Fang, 2009; Namvar et al., 2010; Sharabati et al., 2010; Shih et al., 2010; Vergauwen et al., 2007). Human capital is considered as the heart of intellectual capital (Khalique et al., 2011c). Where in relational capital or customer capital consist of customer satisfaction, loyalty and network. Customer capital is essential, as they are the key sources of revenue generation during the purchase of product and (Khalique et al., 2011a). Generally, structural capital of organizations comprises infrastructure, system policies and procedures (Khalique et al., 2011b).

\subsection{Liberalisation}

Liberalisation is the act of making less strict or relaxation of international trade. Trade liberalisation Southeast Asian countries that are part of cooperation Asean Economic Community (AEC) will be effective on December 31, 2015 (Das et al., 2013). Liberalisations with the existence of supportive governmental policies are imperative and significant for SMEs growth. However, at present, SMEs in Malaysia appear are forced in competing within own country with the players abroad without government protection. It is worst with the introduction of Competition Act 2010. Originally, the aim of this act is to protect economic development and consumer interest through preventing anticompetitive practices and abuse of a dominant position. Yet, the SMEs readiness is a huge question mark whether they are able to sustain or collapse easily.

Certainly, liberalisation is an easy access and allows no barrier in penetrating new business in the foreign countries. Nonetheless, what are on paper would not be the similar with practices. The existence numbers of laws and rules or stipulation 
regulating businesses that led to high level bureaucracy destroying the performance caused by business environment. Lacking of readiness of other countries retarded SMEs expanding abroad while most of foreign player a successfully expanding in this country. The inequality is seen across the borders; the SMEs have no choice but to equip their capability and competence in this new environment.

Undoubtedly, On the other hand, liberalisation benefits tremendously to SMEs when it enables the firms to learn from their global ventures and exploiting opportunities in foreign markets further which strengthen competitiveness. Nevertheless, the affiliation of competition with the international origin businesses with local firms especially SMEs would positively change the working culture, for instance the innovation culture, transferring and adapting new technology locally which led to better survival, increasing profits and growth which includes capability and competency building.

\subsection{Performance}

Performance of SMEs is all about attaining the aims for the final direction businesses regardless of disciplines or sectors. It is for sure that all businesses are looking for success as there is not much different between them. However, a performance measurement of many SMEs has not been well established as compared to large firms. Even though, plenty definition of performance enhancement measurement, yet the utmost factors that SMEs' performance success factor which is highly considered is on the financial issue.

Precisely, performance are determined by two mechanisms consist of financial and non-financial or qualitative measures. Both are interdependent for the success performance of the SMEs. For instance, customer satisfaction could not be measured by a firm by monetary value. Although, the elements of indicators classified under different sections, this study, the author has chosen to adopt model that consists of the following performance measurement indicators: (1) operational performance measurement that consists of the organization's internal operation such as productivity, product quality and customer satisfaction and (2) business performance measured by the enlarged domain of performance related to financial and marketing aspects such as sales growth, profitability and market shares. Researchers testing performance should include performance measures such as market share, sales growth and profitability (Simpson et al., 2012).

\section{Theoretical model}

Fig. 3 depicts the hypothesized model that links the SMEs capabilities in the world market. The proposed theoretical construct of SMEs competitive competencies refers to internationalisation, clustering efficiency, innovation, global food demand and access to finance in Malaysian context by
Othman et al. (2010). However, innovation factor is remain with two more introduction of variables to replace clustering efficiency and access to finance where both are covers in variables of quality and innovation. Whereas, intellectual capital is introduce to suit with the new economy transformation. Besides SMEs' competitive capability in the world market refers to the internationalisation and liberalisation challenges which cover the overall objective of this study. The proposed constructs to be further investigated for a complete set of measurement as the dimension of factors that enhance the SMEs services sectors.

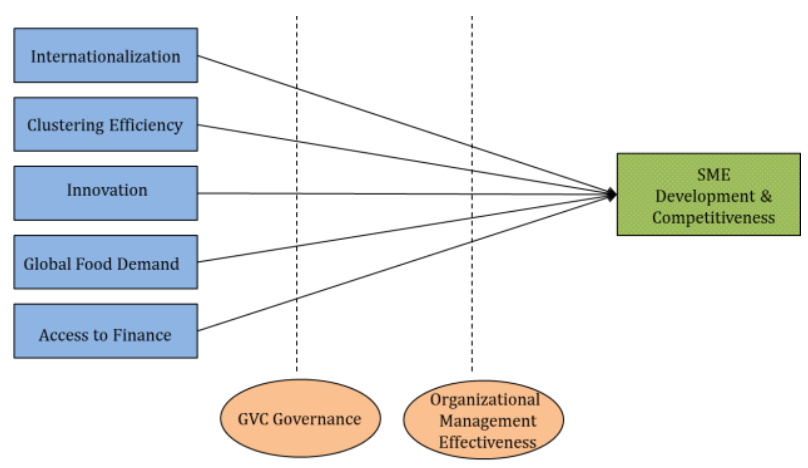

Fig. 3: Industrial dynamics and the evolution of Malaysia SMEs' competitive capabilities in the world market-A value chain approach focusing on the food process sector

\section{Methodology}

The SPSS Statistics software version 2.0 with the demographic profile of the respondents will be analysed. Then, in exploratory factor analysis (EFA), the underlying items of each factor are identified. Upon completion of the EFA, the items were loaded onto factors with eigenvalues greater more than 1.0. Once iterations and deletion of items are completed, the item will be grouped into their constructs. Next, reliability analysis is conducted by measuring the value of Cronbach's $\alpha$ to ensure the internal consistency of the developed set of items at the acceptable minimum value of 0.60 .

Factorial analysis will be firstly analyzed in reducing the complexity of a multivariable data set for the development of theory (Schuyler, 2012). The correlation among a large number of items would be analyzed. The items which contribute with highly correlated would be grouped into a few representative constructs or factors, while uncorrelated items were deleted. The resulting constructs were then analyzed using structural equation modeling (SEM) in order to determine their significance and the best predicators of challenges and enhancement factors for SMEs services sectors.

\section{Discussion and conclusion}

This paper has described the conceptual framework relating to the importance of factors that enhance performance of SMEs services sectors by incorporating between the relationships of the independent and dependent variables. As the 
existing literature reveals the importance of SMEs challenges factors towards business performances, this paper thus argues that this integration relationship can be more improved. However, this is just a conceptual paper; it suggests that an empirical study should be conducted in future by using this conceptual framework to see the impact of the moderators or mediators integration between the SMEs toward business performance.

\section{Acknowledgment}

This paper has been supported by the Ministry of Education Malaysia through its MyBrain2015 scholarship and Technical University Melaka, Malaysia.

\section{References}

Beyza E, Ta F, and Apak S (2014). A research on determining innovation factors for SMEs. Procedia-Social and Behavioral Sciences, 150: 202-211.

Chen YS (2008). The positive effect of green intellectual capital on competitive advantages of firms. Journal of Business Ethics, $77(3):$ 271-286.

Chu PY, Lin YL, Hsiung HH, and Liu TY (2006). Intellectual capital: An empirical study of ITRI. Technological Forecasting and Social Change, 73(7): 886-902.

Cuadrado RJR (2013). Service industries and regions, growth, location and regional effects. Springer, Berlin, Germany.

Dadfar H, Dahlgaard JJ, Brege S, and Alamirhoo A (2013). Linkage between organisational innovation capability product platform development and performance. Total Quality Management, 24(7): 819-834.

Das KD (2010). Another perspective of globalisation. Journal of International Trade Law and Policy, 9(1): 46-63.

Das SB, Menon J, Severion Ro, and Shrestha O (2013). The ASEAN economic community a work in progress. Institute of Southeast Asian Studies, Singapore.

Fariza H (2015). SMEs' impediments and developments in the internationalization process. World Journal of Entrepreneurship, Management and Sustainable Development, 11(2): 100-119.

Fritsch DJ and Storey M (2014). Entrepreneurship in a regional context: Historical roots, recent developments and future challenges. Regional Studies, 48(6): 939-954.

Herremans IM, Isaac RG, Kline TJ, and Nazari JA (2011). Intellectual capital and uncertainty of knowledge: Control by design of the management system. Journal of Business Ethics, 98(4): 627-640.

Hsu YH and Fang W (2009). Intellectual capital and new product development performance: The mediating role of organizational learning capability. Technological Forecasting and Social Change, 76(5): 664-677.

June S and Khar KY (2014). Innovative work behavior (IWB) in the knowledge intensive business services (KIBS) sector in Malaysia: The effect of leader-member exchange (LMX) and social capital (SC). Asian Social Science, 10(2): 172-182.

Khalique M, Hassan I, Jamal NS, and Ageel A (2011a). Challenges faced by the small and medium enterprises (SMEs) in Malaysia: An intellectual capital perspective. International Journal of Current Research, 33(6): 398-401.

Khalique M, Nassir S JA, Hassan A, Isa M, Ageel A, Sarawak M, and Student $P$ (2011b). Relationship of Intellectual capital with the organizational performance of pharmaceutical companies in
Pakistan. Australian Journal of Basic and Applied Sciences, 5(12): 1964-1969.

Khalique M, Shaari JAN, Md IAHB, and Ageel A (2011c). Role of intellectual capital on the organizational performance of electrical and electronic SMEs in Pakistan. International Journal of Business Management, 6(9): 253-257.

Kumar GR and Singh R (2012). Liberalization impact on Indian small industries: An empirical study of Punjab. International Business Intelligent Journal, 5(1): 113-122.

Lisboa A, Skarmeas D, and Lages C (2011). Entrepreneurial orientation, exploitative and explorative capabilities, and performance outcomes in export markets: A resource-based approach. Industrial Marketing Management, 40(8): 12741284.

Love J and Roper S (2015). SME innovation, exporting and growth: A review of existing evidence. International Small Business Journal, 33(1): 28-48.

Mazzarol T, Volery T, Doss N, and Thein V (1999). Factors influencing small business start- ups: A comparison with previous research. International Journal of Entrepreneurial Behaviour and Research, 5(2): 48-63.

Michael EB and Milambo K (2010). How can economic and political liberalization improve financial development in African countries. Journal of Financial Economic Policy, 2(1): 35-59.

MIER (2011). Services the next growth engine?. Malaysian Institute of Economic Research, Kuala Lumpur, Malaysia. Available online at: http://www.mier.org.my

MITI (2011). ETP annual report. Ministry of International Trade and Industry, Kuala Lumpur, Malaysia.

MITI (2012). ETP annual report. Ministry of International Trade and Industry, Kuala Lumpur, Malaysia.

Namvar M, Fathian M, Akhavan P, and Reza GM (2010). Exploring the impacts of intellectual property on intellectual capital and company performance: The case of Iranian computer and electronic organizations. Management Decision, 48(5): 676697.

Obokoh LO (2008). Small and medium sized enterprises devolpment under trade liberalisation: A survey of Nigerian Experience. International Journal of Business Management, 3(12): 92-101.

Othman Z, Vandenbempt K, and Hendrickx E (2010). Industrial dynamics and the evolution of Malaysian SME's competitive capabilities in the world market-A value chain approach focusing on the food processing sector. In the the Globelics 2010, $8^{\text {th }}$ International Conference, Kuala Lumpur, Malaysia: $1-29$.

Parasuraman A, Zeithaml VA, and Berry LL (1988). Servqual. Journal of retailing, 64(1): 12-40.

Popli GK (2010). Trade liberalization and the self employed in Mexico. World Development Journal, 38(6): 803-813.

Schuyler W (2012). Reading statistics and research. Pearson Education Inc, Massachusetts, USA.

Schwab K (2014). The global competitiveness report. World Economic Forum, Geneva, Switzerland.

Sharabati AA, Naji Jawad S, and Bontis N (2010). Intellectual capital and business performance in the pharmaceutical sector of Jordan. Management Decision, 48(1): 105-131.

Shih KH, Chang CJ, and Lin B (2010). Assessing knowledge creation and intellectual capital in banking industry. Journal of Intellectual Capital, 11(1): 74-89.

Simpson M, Padmore J, and Newman N (2012). Towards a new model of success and performance in SMEs. International Journal of Entrepreneurial Behavior and Research, 18(3): 264-285. 
Soininen J, Martikainen M, Puumalainen $\mathrm{K}$, and Kyläheiko,K (2012). Entrepreneurial orientation: Growth and profitability of Finnish small and medium sized enterprises. International Journal of Production Economics, 140(2): 614-621.

Talib H, Ali K, and Idris F (2013). Quality management framework for the SME's food processing industry in Malaysia. International Food Research Journal, 20(1): 147-164.
Vergauwen P, Bollen L, and Oirbans E (2007). Intellectual capital disclosure and intangible value drivers: An empirical study. Management Decision, 45(7): 1163-1180.

WTO (2016). Services: Rules for growth and investment. World Trade Organisation, Geneva, Switzerland. Available online at: https://www.wto.org/english/thewto_e/whatis_e/tif_e/agrm 6_e.htm 